\title{
Les télomères interstitiels et leur rôle éventuel dans la genèse des sites fragiles de I'ADN
}

Une brève parue il y a un an $(\mathrm{m} / \mathrm{s}$ $n^{\circ} 9$, vol. 4, p. 592) annonçait l'identification des séquences télomériques des chromosomes humains. Cette séquence est formée de six bases répétées 500 à 2000 fois. Cette séquence, TTAGGG, et une autre voisine, TTGGGG, sont très conservées au cours de l'évolution. Les télomères jouent un rôle essentiel dans la stabilité des chromosomes, et probablement aussi lors de la méiose car ce sont eux qui s'attachent à la membrane nucléaire, région où débute l'appariement des chromosomes homologues.

L'idée de «télomères interstitiels », c'est-à-dire de séquences télomériques ayant migré à l'intérieur des chromosomes, peut paraître paradoxale. On peut cependant imaginer leur apparition à la suite de translocations s'effectuant par fusion de télomères appartenant à des chromosomes différents. Ces fusions en tandem semblent fréquentes dans les cancers, où des remaniements chromosomiques sont de règle; on les a trouvées d'abord dans des leucémies, puis dans des tumeurs solides. Mais il est possible que chez des individus normaux on trouve des séquences télomériques ailleurs qu'aux extrémités. L'exemple qui vient à l'esprit est celui du chromosome 2 chez l'homme : ce chromosome de grande taille résulte de la fusion de deux acrocentriques qui sont présents chez tous les autres hominidés. Il serait donc logique de rencontrer des séquences télomériques aux points de fusion et; de fait, c'est ce que suggère une hybridation in situ, trouvée en position 2qll-ql4. Comme cette région contient deux sites fragiles, des chercheurs écossais ont fait l'hypothèse que des répétitions en tandem de séquences télo- de cette fragilité et ont entrepris de recenser les arguments qui rendent cette idée plausible [1].

Si l'on introduit des répétitions télomériques de Tetrahymena dans un site interne de chromosome de levure, on provoque fréquemment une rupture du chromosome [2]. Chez l'homme, il existe un cas semblable dans la littérature [1]. Dans un cas de fusion 6-19, sur plusieurs centaines de métaphases examinées dans le génome entier, plus du tiers des cassures de chromosome se faisait en ce point de fusion. Est-il possible d'étendre cette observation unique à d'autres sites fragiles? Un premier argument est que les télomères possèdent, sur un brin, une structure riche en GT, alors qu'une telle prédominance de GT a été proposée pour les sites fragiles. En outre, les sites fragiles pourraient être particulièrement susceptibles aux recombinaisons, ce qui est une propriété connue des télomères, comme cela a été notamment démontré pour Saccharomyces cerevisiae [3].

Chez les mammifères, cette propriété de recombinaison est portée à son plus haut point par les minisatellites qui donnent des répétitions en tandem à nombre variable (variable number of tandem repeats, VNTR), support habituel des «empreintes génétiques». Or la plupart des familles de minisatellites qui ont été clonées ont une proportion élevée de $G$ sur un brin. Les tractus de télomères interstitiels, comme les minisatellites, sont riches en G. Les fragments de haut poids moléculaire qui s'hybrident avec la sonde (TTGGGG)n possèdent eux aussi une taille très variable selon les individus. Il est donc vraisemblable, bien que non démontré, que ces variants sont engendrés par recombinaison entre des répétitions de séquences télomériques interstitielles. Enfin l'idée que des télomères interstitiels pourraient subir des recombinaisons au cours de la méiose est en accord avec une expérience effectuée sur le parasite Plasmodium falciparum par Vernick et al. [4]. Si dans cette espèce on croise des individus d'origine génétique différente, on constate que des séquences analogues à celles des télomères sont instables : beaucoup de descendants montrent des fragments de restriction absents des deux parents, dont certains proviennent de réarrangements à des positions internes des chromosomes. Au contraire, si les parasites sont tous de la même souche, on ne trouve aucune instabilité. Une hypervariabilité provient donc d'événements moléculaires qui ont lieu lors de la réduction méiotique, mais elle ne se révèle que quand on croise des souches hétérologues $\mathrm{du}$ parasite. Cette instabilité est 100 fois plus fréquente que celle qu'on détecte dans les minisatellites de mammifères.

Ces travaux révèlent des potentialités insoupçonnées des séquences télomériques, à vrai dire encore assez largement spéculatives. Il reste aux recherches ultérieures à les confirmer et à en préciser l'importance.

J.C.D.

1. Hastie ND, Allshire RC. Human telomeres: fusion and interstitial sites. Trends Genet 1989; 5 : 326-31.

2. Murray AW, Claus TE, Szostak JW. Characterization of two telomeric DNA processing reactions in Saccharomyces cerevisiae. Mol Cell Biol 1988; 8 : 4642-50.

3. Pluta AF, Zakian VA. Recombination occurs during telomere formation in yeast. Nature 1989; 337 : 429-33.

4. Vernick KD, Walliker D, McCutchan TF Genetic hypervariability of telomere related sequences is associated with meiosis in Plasmodium falciparum. Nucleic Acids Res 1988 ; $16: 6973-85$. 